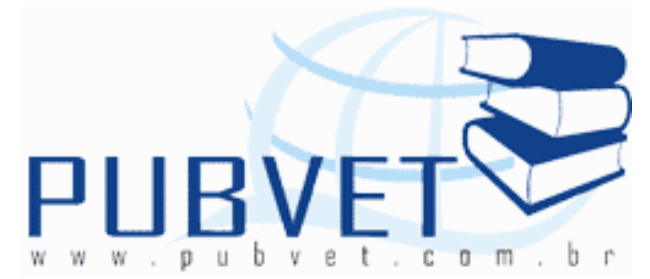

PUBVET, Publicações em Medicina Veterinária e Zootecnia.

\title{
Lobos pulmonares e formação dos brônquios do gato mourisco (Herpailurus yagouaroundi - Severtzow, 1848) (Felidae)
}

\author{
André Luiz Quagliatto Santos ${ }^{1}$, Flávio Machado de Moraes ${ }^{1}$, Saulo Fernandes \\ Mano de Carvalho1, Lorena Tannús Menezes ${ }^{2}$, Arthur Paulino Sanzo \\ Kaminishi $^{2}$, Tatiana Grillo Leonardo ${ }^{2}$, Liliane Rangel Nascimento ${ }^{2}$
}

Laboratório de Ensino e Pesquisas em Animais Silvestres - LAPAS, FAMEV/UFU, e-mail: quagliatto@famev.ufu.br 1. Docentes. 2. Mestrandos.

\section{Resumo}

Os pulmões são órgãos respiratórios pares, direito e esquerdo e divididos em lobos por profundas fissuras interlobares. O pulmão direito possui quatro lobos: cranial, médio, caudal e acessório. É maior do que o pulmão esquerdo, e este é dividido em parte cranial do lobo cranial, parte caudal do lobo cranial e lobo caudal. O conhecimento da morfologia destes orgãos nesta espécie silvestre nos auxilia no tratamento de moléstias respiratórias, cirurgias, cateterismo e até a auscultação. Um gato mourisco, fêmea que veio á óbito por morte natural do Zoológico Parque do Sabiá, Uberlândia-MG, foi encaminhado ao LAPAS. Este foi fixado em formol à $10 \%$ e seus pulmões e traquéia foram retirados para pesquisa. A traquéia de divide em brônquios principais direito e esquerdo. $O$ direito se subdivide em brônquios lobares cranial, médio, acessório e caudal. O lobar cranial emite os brônquios segmentares cranial e caudal, o lobar médio emite os segmentares dorsal e 
SANTOS, A.L.Q. et al. Lobos pulmonares e formação dos brônquios do gato mourisco (Herpailurus yagouaroundi - Severtzow, 1848) (Felidae). PUBVET, Londrina, V. 5, N. 13, Ed. 160, Art. 1083, 2011.

ventral, o lobar acessório emite os segmentares dorsal e ventral, o lobar caudal emite os segmentares basal dorsal, basal ventral, basal lateral, dorsal cranial e dorsal caudal. O esquerdo se subdivide em brônquios lobares cranial e caudal. O lobar cranial emite os segmentares cranial e caudal, o lobar caudal emite os segmentares basal dorsal, basal ventral, basal lateral, dorsal cranial e dorsal caudal.

Palavras chave: Pulmão, brônquios, traquéia, Herpailurus yagouaroundi.

\title{
Pulmonary lobes and bronchi branching of jaguarundi (Herpailurus yagouaroundi - Severtzow, 1848) (Felidae)
}

\begin{abstract}
The lungs are twin respiratory organs, right and left and have lobes divided with deep fissures. The right lung is larger than the left lung. The right lung has four lobes: cranial, middle, acessory and caudal. The left lung has two lobes: cranial, with cranial pars and caudal pars, and caudal. Kwnolegments about the morphology of this organ in that wild cat auxiliary many procedings: in treatments of lungs diseases, surgery, cateterism and auscultation. A female jaguarondi died of natural causes in the Zoo of the Sabiá Park, Uberlândia-MG, Brazil, came to LAPAS. That was fixed in formaldehyde $10 \%$ and your lungs and trachea was removed to this research. The trachea divided in right principal bronchi and left principal bronchi. The right principal bronchi subdivide in cranial lobar bronchis, middle, acessory and caudal. The cranial lobar emit the segmentars cranial bronchies and caudal, the middle lobar emit the segmentars dorsal and ventral, the acessory lobar emit the segmentars dorsal and ventral, the caudal lobar emit the segmentars dorsal basal, ventral basal, lateral basal, cranial dorsal and caudal dorsal. The left principal bronchi subdivide in cranial bronchi lobars and caudal. The cranial lobar emit the segmentars cranial and caudal, the caudal lobar emit segmentars dorsal basal, ventral basal, lateral basal, cranial dorsal e caudal dorsal.
\end{abstract}

Keywords: Lungs, bronchi, trachea, Herpailurus yagouaroundi. 
SANTOS, A.L.Q. et al. Lobos pulmonares e formação dos brônquios do gato mourisco (Herpailurus yagouaroundi - Severtzow, 1848) (Felidae). PUBVET, Londrina, V. 5, N. 13, Ed. 160, Art. 1083, 2011.

\section{INTRODUÇÃO}

Em anatomia e cirurgia, a segmentação indica a porção do órgão que é independente em irrigação e drenagem, separado das outras porções, cirurgicamente removível e morfologicamente identificável. Nos pulmões além da irrigação e drenagem, devemos também considerar a segmentação dos brônquios. No pulmão o segmento tem a mesma função do órgão que este faz parte e possui a sua organização, drenagem e divisão dos brônquios em satélite acompanhando os segmentos de sua arquitetura. Assim os segmentos anatomocirúrgicos são partes independentes no parênquima deste órgão (DI DIO, 1998).

Bruni e Zimmerl (1951), dividem o pulmão em direito e esquerdo. No pulmão direito temos os lobos: apical, cardíaco, basal e ázigo e no pulmão esquerdo parte apical e parte cardíaca do lobo apical e lobo caudal.

Dyce et al. (1997) descreve que o pulmão direito de carnívoros é constituído por lobos cranial, médio, caudal e acessório. O pulmão esquerdo é subdividido em lobo cranial, partes cranial e caudal e lobo caudal.

Getty (1986) subdivide os lobos dos pulmões dos carnívoros pelas fissuras interlobulares profunda. O pulmão direito é formado por quatro lobos: apical (cranial), médio (cardíaco), caudal (diafragmático) e acessório (ázigos ou intermediário) e este é maior do que o pulmão esquerdo, que se divide em dois lobos: apical (cranial) e diafragmático (caudal). Os brônquios se dividem em principais direito e esquerdo. O brônquio principal direito emite os brônquios lobares apical direito, médio direito, acessório e diafragmático direito. O brônquio principal esquerdo emite os brônquios lobares apical esquerdo e diafragmático esquerdo. Cada brônquio lobar se subdivide no interior dos lobos dando brônquios segmentares. Então temos: a) Brônquio lobar apical direito emitindo os brônquios segmentares caudal e cranial e este último emite uma série de brônquios subsegmentares dorsais e craniais, no qual o dorsal é maior. B) Brônquio lobar médio direito emitindo os brônquios segmentares dorsal e ventral. C) brônquio lobar acessório emitindo os brônquios segmentares dorsal e ventral. D) brônquio lobar diafragmático 
SANTOS, A.L.Q. et al. Lobos pulmonares e formação dos brônquios do gato mourisco (Herpailurus yagouaroundi - Severtzow, 1848) (Felidae). PUBVET, Londrina, V. 5, N. 13, Ed. 160, Art. 1083, 2011.

direito emitindo os brônquios segmentares basal ventral, basal lateral, dorsal cranial, dorsal caudal e basal dorsal. E) Brônquio lobar apical esquerdo emitindo os segmentares cranial e caudal. F) Brônquio lobar difragmático esquerdo emitindo os segmentares basal ventral, basal lateral, dorsal cranial, dorsal caudal e basal dorsal. Sobre a traquéia, este autor cita que o gato doméstico possui de 38 à 43 anéis, inicia-se na Segunda vértebra torácica e se bifurca em brônquios principais entre o quarto e quinto espaços intercostais.

Light (1993), Jaramillo e Valdebenito (2006) descrevem a mesma divisão lobar em felinos.

As artérias pulmonares e os brônquios seguem trajetos topográficos interrelacionados no interior dos pulmões. Bausch et al. (2000) estudou 36 pulmões de gatos e identificou que o número de artérias que emergem da artéria pulmonar e das artérias lobares caudais são maiores em número do que do que os brônquios emergentes correspondentes nos seus respectivos lobos.

Os pulmões também são alvos de vermes, Grabarevic et al. (1999) pesquisou vermes pulmonares em gatos entre zonas urbanas e rurais. Larvas e ovos do Aelurostrongylus abstrussus foram detectadas nos alvéolos, brônquiolos e brônquios (FERREIRA da SILVA et al., 2005; FERREIRA et al., 2007).

Mitchell et al. (2000) revisaram diagnósticos de ruptura traqueal dividido a intubação com sondas para realização de anestesia inalatória. Em um total de 20 gatos, todos apresentavam pneumomediastino e enfisema subcutâneo. 15 apresentaram dispnéia moderada e 4 com dispnéia severa.

O objetivo deste estudo foi identificar os lobos pulmonares e quais brônquios ventilam estes lobos na espécie Herpailurus yagouaroundi.

\section{MATERIAL E MÉTODO}

Um gato mourisco, adulto, fêmea, proveniente de morte natural do Zoológico Parque do Sabiá, Uberlândia-MG, foi fixado em formol 10\%. Após incisão de pele e músculos da parede ventral do tórax e pescoço, vizualizou-se a traquéia e pulmões na cavidade torácica. Com auxílio de um paquímetro 
SANTOS, A.L.Q. et al. Lobos pulmonares e formação dos brônquios do gato mourisco (Herpailurus yagouaroundi - Severtzow, 1848) (Felidae). PUBVET, Londrina, V. 5, N. 13, Ed. 160, Art. 1083, 2011.

universal Starrett, mensurou-se o comprimento da traquéia, seus diâmetros internos no terço proximal, médio e distal, número de anéis e seu início e fim foram relacionados com as vértebras torácicas e os espaços intercostais. Nos pulmões tomou-se o comprimento e largura de cada lobo. Então os pulmões e traquéia foram retirados para dissecação. Pela face medial dos pulmões, o seu parênquima foi cuidadosamente retirado com auxílio de pinça histológica acompanhando o trajeto dos brônquios no interior dos lobos pulmonares e identificando-os.

\section{RESULTADOS}

Os pulmões do gato mourisco se divide por profundas fissuras interlobares. O direito se divide em lobos cranial, médio, acessório e caudal. O esquerdo divide-se em lobo cranial, com partes cranial e caudal e lobo caudal. O pulmão direito é ventilado pelo brônquio principal direito este emite brônquios lobares para cada lobo, sendo: brônquio lobar cranial ventilando o lobo cranial, brônquio lobar médio ventilando o lobo médio, brônquio lobar acessório ventilando o lobo acessório e brônquio lobar caudal ventilando o lobo caudal. Cada brônquio lobar se subdivide em segmentares, sendo: brônquio lobar cranial se subdividindo em brônquios segmentares caudal e cranial (e este em dorsais e ventrais), brônquio lobar médio se subdividindo em dorsal e ventral, brônquio lobar acessório se subdividindo em segmentares dorsal e ventral, brônquio lobar caudal se subdividindo em segmentares basal dorsal, basal ventral, basal lateral, dorsal cranial, dorsal caudal. O pulmão esquerdo é ventilado pelo brônquio principal esquerdo emitindo os brônquios lobares cranial e caudal, o lobar cranial se subdividem em segmentares cranial e caudal, o lobar caudal se subdivide em segmentares basal dorsal, basal ventral, basal lateral, dorsal cranial e dorsal caudal. No pulmão direito temos as seguintes medidas: $49 \mathrm{~mm}$ de comprimento e $41 \mathrm{~mm}$ de largura para o lobo cranial, $20 \mathrm{~mm}$ de comprimento e $46 \mathrm{~mm}$ de altura para o lobo médio, $51 \mathrm{~mm}$ de comprimento e $40 \mathrm{~mm}$ de altura para o lobo caudal. O comprimento total deste pulmão foi de $111 \mathrm{~mm}$. Este pulmão se situava entre as segunda e décima 
SANTOS, A.L.Q. et al. Lobos pulmonares e formação dos brônquios do gato mourisco (Herpailurus yagouaroundi - Severtzow, 1848) (Felidae). PUBVET, Londrina, V. 5, N. 13, Ed. 160, Art. 1083, 2011.

primeira costelas na cavidade torácica. No pulmão esquerdo: $41 \mathrm{~mm}$ de comprimento e $42 \mathrm{~mm}$ de altura para a parte cranial do lobo cranial, $43 \mathrm{~mm}$ de comprimento e $47 \mathrm{~mm}$ de altura para o lobo caudal. O comprimento total deste pulmão foi de $100 \mathrm{~mm}$. Este se situava entre a segunda e a décima costela na cavidade torácica.

A traquéia apresentou 48 anéis $(145,60 \mathrm{~mm})$, sendo 29 anéis cervicais $(87,15 \mathrm{~mm}), 19$ anéis torácicos $(58,45 \mathrm{~mm})$. Os diâmetros internos foram: $6,70 \mathrm{~mm}$ na porção proximal, 9,75mm na porção média e 9,00mm na porção distal. A traquéia iniciou-se na segunda vértebra cervical e bifurcou-se em brônquios principais entre a sexta e sétima costelas, ou seja, no sexto espaço intercostal na altura da sexta vértebra torácica.

\section{DISCUSSÃO}

O gato mourisco apresenta dois pulmões: direito e esquerdo. O direito possui quatro lobos divididos por fissuras interlobares profundas: cranial, médio, acessório e caudal. O pulmão esquerdo possui dois lobos: cranial com partes cranial e caudal e lobo caudal. Com uma pequena variação na nomenclatura, Dyce et al. (1997); Getty (1986); Di Dio (1998), também encontraram o mesmo número de pulmões e lobos em carnívoros.

A ventilação dos lobos pelos brônquios lobares e sua segmentação em lobos segmentares no gato mourisco segue o mesmo modelo encontrado por Getty (1986) e Oliveira et al. (2001) em gato doméstico. Porém a traquéia do gato mourisco apresentou 48 anéis, iniciou-se na segunda vértebra cervical e bifurcou-se em brônquios principais no sexto espaço intercostal, este autos cita que o gato doméstico possui entre 38 à 43 anéis traqueais, inicia-se na segunda vértebra cervical e bifurca-se no quarto ou quinto espaço intercostal.

Nowak (1991) indica que o gato mourisco possui de $550-770 \mathrm{~mm}$ de comprimento de cabeça e corporal. Este exemplar apresentou $576,5 \mathrm{~mm}$ de comprimento de cabeça e corporal.

Blond et al. (2001) utilizou radiografia para detectar tumores em cães e gatos, a técnica de radiografar e conhecimentos em morfologia dos pulmões, 
SANTOS, A.L.Q. et al. Lobos pulmonares e formação dos brônquios do gato mourisco (Herpailurus yagouaroundi - Severtzow, 1848) (Felidae). PUBVET, Londrina, V. 5, N. 13, Ed. 160, Art. 1083, 2011.

traquéia e brônquios foram úteis para detectar os tumores. Calixto et al. (2007) também utilizou o estudo radiográfico para detectar efusão pleural advindo de torção do lobo pulmonar em gatas. Silva (2006) utilizou a radiografia torácica para detectar bronquite alérgica em gatos.

Das neoplasias pulmonares o carcinoma ocorre com grande frequência, Yener et al. (2001) estudaram carcinomas broncoalveolares em gatos, houve necessidade de utilizar conhecimentos claros de anatomia.

Monnet (2001) e Ishizaki et al. (2005) necessitou de conhecimentos anatomocirurgicos para realizar cirurgias em gatos e cães tais como a lobectomia pulmonar.

A radiografia mostrou a evidência de neoplasia pulmonar focal em três gato com hipertiroidismo (COOK et al., 1993), utilizando conhecimentos de anatomia.

Hahn e Mcentee (1997) se dispuseram de conhecimentos de morfologia para classificar neoplasias pulmonares em 86 gatos. Os tumores foram classificados em bronquiais e brônquio-alveolares.

Garnier (2001) descreve a intubação orotraqueal em cães e gatos. O autor chama atenção no cuidado da escolha do diâmetro do tubo traqueal ser adequado ao diâmetro da traquéia.

Wong e Brock (1994), Jaramillo e Valdebenito (2006) discutem as complicações pelo uso de tubos traqueais inadequados ao diâmetro da traquéia, em gatos. Os estudos acima mostram que se deve conhecer a anatomia e o diâmetro da traquéia para o sucesso da intubação orotraqueal, que é necessária para o uso de anestesia inalatória.

\section{CONCLUSÕES}

A arquitetura da árvore brônquica do gato mourisco com suas segmentações é semelhante à do gato doméstico.

A traquéia do gato mourisco apresentou 48 anéis $(145 \mathrm{~mm}$ de comprimento total), sendo 29 anéis cervicais $(87,15 \mathrm{~mm})$ e 19 anéis torácicos 
SANTOS, A.L.Q. et al. Lobos pulmonares e formação dos brônquios do gato mourisco (Herpailurus yagouaroundi - Severtzow, 1848) (Felidae). PUBVET, Londrina, V. 5, N. 13, Ed. 160, Art. 1083, 2011.

$(58,45 \mathrm{~mm})$. Iniciou-se na segunda vértebra cervical e bifurcou-se no sexto espaço intercostal noa altura da sexta vértebra cervical.

\section{REFERÊNCIAS}

BAUSCH, M.; KOCH, R.; WAIBL, H. Ramification of the feline pulmonary arteries: anatomy and angiography. Kleintierpraxis, German, v.45, n.4, p.275-284, Fev. 2000.

BLOND, L.; BEAUREGARD, G.; BRETON, L. Chest radiography from three directions for detecting lung tumours in dogs and cats. Medecine Veterinaire du Quebec, Quebec, v.31, n.3, p.136-137, May 2001.

BRUNI, A. C.; ZIMMERL, U. Anatomia degli animali domestici. Milano: Francesco Vallardi, 1951 , p. $133-140$.

CALIXTO, R.; SOUZA, H. J. M.; CORGOZINHO, K. B. Quilotórax associado à torção de lobo pulmonar em gata. Acta Scientiae Veterinariae, Porto Alegre, v. 35, n.2, p. 233-237, Fev. 2007.

COOK, S. M.; DANIEL, G. B.; WALKER, M. A.; MADDUX, J. M.; JENKINS, C. C.; KLEBANOW, E. R.; BOULEY, D. M.; DEAN, D. F.; PETERSEN, M. G. Radiographic and scintigraphic evidence of focal pulmonary neoplasia in three cats with hiperthyroidism: diagnostic and therapeutic considerations. Journal of Veterinary Internal Medicine, Philadelphia, v.7, n.5, p.303-308, Jan./Mar. 1993.

DI DIO, L. A. Tratado de anatomia aplicada I. São Paulo: Pólus Editorial, 1998, p. 83-84.

DYCE, J. M.; SACK, W. O.; WENSING, C. I. G. Tratado de anatomia veterinária. Rio de Janeiro: Guanabara Koogan, 2ed., 1997, p.127-131.

FERREIRA, A. M. R.; SOUZA-DANTAS, L. M.; LABARTHE, N. Registro de um caso de Aelurostrongylus abstrusus (Railliet, 1898) em um gato domestico no Rio de Janeiro, RJ (Nota previa). Brazilian Journal Veterinary Research Animal and Science, São Paulo, v. 44, n.1, p.24-26, Fev. 2007.

FERREIRA DA SILVA, J. M., PEREIRA DA FONSECA, I. M., MADEIRA DE CARVALHO, L. M., MEIRELES, J. A. F. S. E FAZENDEIRO, I. Pneumonia em gato por Aelurostrongylus abstrusus necessidade de um diagnóstico precoce. Revista Portuguesa de Ciências Veterinárias, Portugal, v.100, n.553-554, p.103-106, Abr. 2005.

GARNIER, E. Orotracheal intubation in dogs and cats. Le Point Vétérinaire, France, v.32, n.212, p.54-56, Dez. 2001.

GETTY, R. Anatomia dos animais domésticos. Rio de Janeiro: Guanabara Koogan, 5ed., 1986 , p. $1474-1480$.

GRABAREVIC, Z.; CURIC, S.; TUSTON, J. A.; ARTUKOVIC, B.; SIMEC, Z.; RAMADAN, K.; ZIVICNJAK, T. Incidence and regional distribution of the lungworm Aelurostrongylus abstrusus in cats in Croatia. Veterinarski Arhiv Es, Croatia, v.69, n.5, p.279-287, Jan. 1999. 
SANTOS, A.L.Q. et al. Lobos pulmonares e formação dos brônquios do gato mourisco (Herpailurus yagouaroundi - Severtzow, 1848) (Felidae). PUBVET, Londrina, V. 5, N. 13, Ed. 160, Art. 1083, 2011.

HAHN, K. A.; MCENTEE, M. F. Primary lung tumors in cats: 86 cases (1979-1994). Journal of the American Veterinary Medical Association, Ithaca, v.211, n.10, p.1257-1260, Nov. 1997.

ISHIZAKI, M. M.; FERREIRA, A. M. R.; SALOMÃO JUNIOR, E.; NASCIMENTO JUNIOR, A.; MARSICO FILHO, F. O n-butil cianoacrilato na lobectomia pulmonar parcial em felinos. Estudo experimental. Ciência Rural, Santa Maria, v.35, n.1, p.109-115, Jan./Fev. 2005.

JARAMILLO, M. G.; VALDEBenito, P. A. Modificaciones del Método de Preparaciones Anatómicas de Pulmones Insuflados. International Journal of Morphology, Temuco, v.24, n.2, p.143-146, Jun. 2006.

LIGHT, G. S. Atlas of feline anatomy for veterinarians. Philadelphia: W.B. Saunders, 1993, p. $135-143$.

MITCHELL, S. L.; MCCARTHY, R.; RUDLOFF, E.; PERNELL, R. T. Tracheal rupture association with intubation in cats: 20 cases (1996-1998). Journal of the American Veterinary Medical Association, Ithaca, v.216, n.10, p.1592-1595, Nov.2000.

MONNET, E. Pulmonary surgery in dogs and cats. Le Point Vétérinaire, France, v.32, n.216, p.24-29, Dez. 2001.

OLIVEIRA, F. S.; BORGES, E. M.; MACHADO, M. R. F.; CANOLA, J. C.; RIBEIRO, A. A. C. M. Segmentação anátomo-cirúrgica arterial dos pulmões de gato (Felis catus domesticus, L., 1758). Brazilian Journal Veterinary Research Animal and Science, São Paulo, v.38, n.6, p. 253-257, Mar. 2001

SILVA, P. M. S. Bronquite Alérgica Felina. São Paulo: Universidade Castelo Branco, 2006, 30f. Monografia (Especialização em Clinica de Pequenos Animais) - Pós-graduação "Lato Sensu" em Clínica de Pequenos Animais, Curso de Medicina Veterinária, Universidade Castelo Branco, São Paulo, 2006.

WONG, W. T.; BROCK, K. A. Tracheal lacerations from endotracheal intubation in a cat. The Veterinary Record, London, v.134, n.24, p.622-624, Jun. 1994.

YENER, Z.; TUTUNCU, M.; YUKSEL, H.; AKKAN, H. Bronchoalveolar carcinoma in a Van cat. Veteriner Bilimberi Dergisi, France, v. 17, n. 3, p. 111-116, Fev. 2001. 